\title{
The influence of switched reluctance generator winding parameters on output power at different rotational speeds
}

\author{
Artur Sliwiński ${ }^{1}$, Krzysztof Wrobel ${ }^{1, *}$ and Krzysztof Tomczewski ${ }^{1}$ \\ ${ }^{1}$ Opole University of Technology, Faculty of Electrical Engineering Automatic Control and Informatics, Opole, Poland
}

\begin{abstract}
The paper presents the influence of the winding parameters of a switched reluctance generator on output power at different rotational speeds. All tested generators were designed on the basis of the same magnetic circuit. In the paper the influence of windings parameters on current and torque dependence on the rotor position angle are shown. The calculations were performed in the authors' own computing environment dedicated to optimisation, based on a two-stage genetic algorithm. A FEMM program was used for magnetostatic calculations, whereas the dynamic calculations were performed on the authors' own simulation program. The basic parameters of the tested generators were determined during the study.
\end{abstract}

\section{Introduction}

The annual electricity production of a wind generator depends on the wind speed distribution at the turbine's location [1]. The power output of a switched reluctance generator (SRG) at different rotational speeds depends on windings parameters and values of commutation angles $[2,3]$. The optimal switch-on and switch-off angles values depends on rotational speed. The paper presents the results of a study on the influence of windings parameters on SRG output power at optimal dependencies of commutation angles vs rotational speed.

The calculations were performed in the developed computing environment based on a genetic algorithm [4]. The environment allows for magnetostatic and simulation calculations, based on autor's and external programs [5]. For optimisation, a genetic algorithm associated with the Matlab program was used. Magnetic circuit calculations were performed using the FEMM program, whereas the simulations were carried out in the authors' own simulation program. Optimisation was performed in two stages. In the first stage, the shape of the magnetic circuit was optimised. The main genetic algorithm (AG1) generates the geometric parameters of the magnetic circuit, on the basis of which the machine model is created in the FEMM program. This program calculates magnetics parameters of SRG.

In the second optimisation stage, a simulation program based on these characteristics was used. At this stage, the secondary genetic algorithm (AG2) optimises windings parameters and the values of commutation angles. This kind of two-stage optimisation limits the number of calculations of the magnetic circuit's variants, but enable faster calculation of optimal windings parameters and commutation angle values for various speeds.
The block diagram algorithm of the computational environment is shown in Fig. 1.

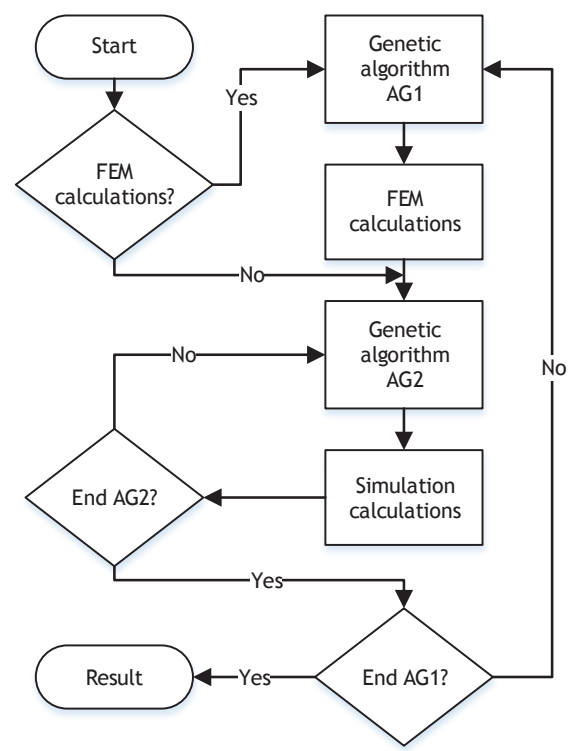

Fig. 1. Schematic diagram of the computational algorithm.

\section{Computational results}

The simulations were performed for a four-phase SRG with 8 stator poles and 6 rotor teeth. The magnetic circuit of the generator was characterised by an outer diameter of $120 \mathrm{~mm}$, an air-gap diameter of $34.3 \mathrm{~mm}$, and an active length of $80 \mathrm{~mm}$. Variables are the diameter of wire $\Phi$ and the number of turns in phase windings $N_{z w}$. The objective function (1) maximises the difference between generated and consumed power $\left(P_{g}\right.$ $\left.P_{c}\right)$, while limiting power losses in the windings $\left(P_{c u}\right)$ and electronics elements $\left(P_{e}\right)$ as well as the maximum current value $\left(I_{\max }\right)(2)$.

\footnotetext{
Corresponding author: k.wrobel@po.opole.pl
} 

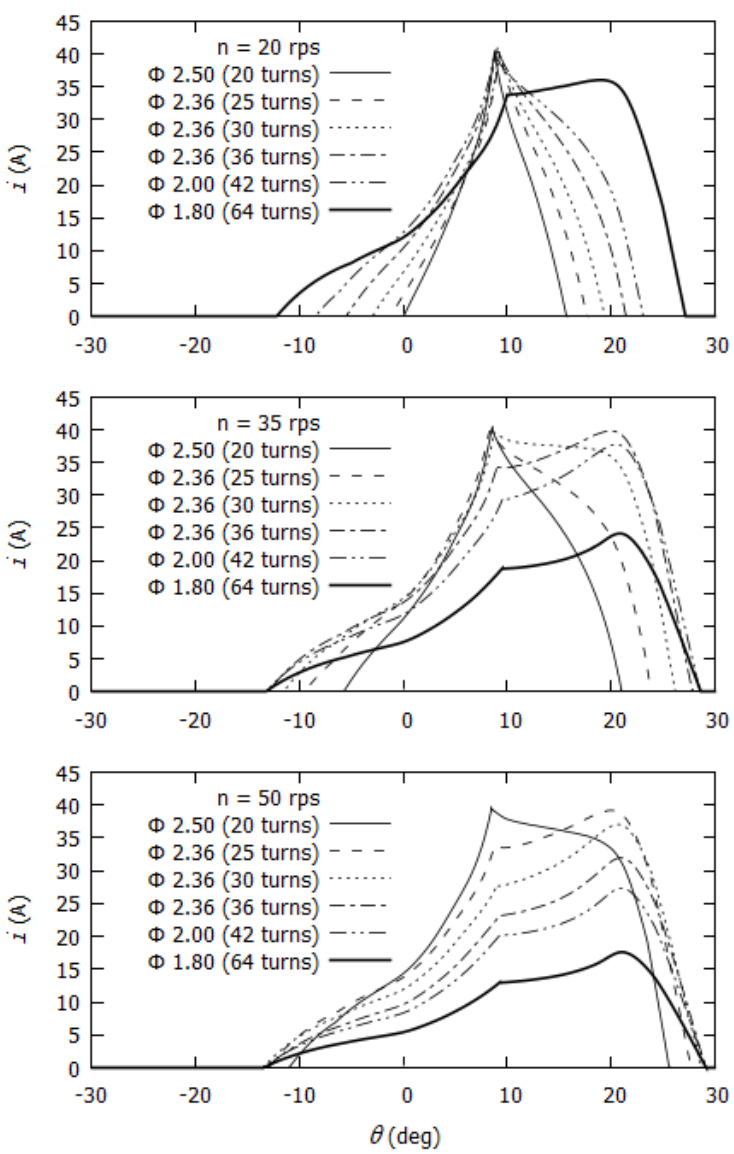

Fig. 2. Dependences of phase current vs rotor position angle for rotational speeds of 20,35 , and $50 \mathrm{rps}$.

$$
\begin{gathered}
f=\left\{\begin{array}{cc}
P_{g}+P_{c u}+P_{e}<1 & \left(P_{g}-P_{c}\right) f_{c}\left(I_{\max }\right) \\
P_{g}+P_{c u}+P_{e} \geq 1 & \frac{P_{g}-P_{c}}{P_{g}+P_{c u}+P_{e}} f_{c}\left(I_{\text {max }}\right)
\end{array}\right. \\
f_{c}\left(I_{\max }\right)=\left\{\begin{array}{cc}
I_{\text {max }}<40 & 1 \\
I_{\max } \geq 40, I_{\max }<50 & -0.009\left(I_{\max }-40\right)^{2}+1 \\
I_{\text {max }} \geq 50 & 0.1
\end{array}\right.
\end{gathered}
$$

Figures 2 and 3 present the dependencies of phasecurrent and electromagnetic torque produced by one motor phase at optimal values of commutation angles.

Table 1 presents: 1 - the number of turns in the phase windings; 2 - the diameter of the winding wire; 3 - the speed at which maximum power was obtained; 4 - the value of this power, 5-7 - the values of power obtained for the tested generators at different speeds.

Table 1. Power generated by the generators with different windings at different speeds.

\begin{tabular}{|c|c|c|c|c|c|c|}
\hline 1 & 2 & 3 & 4 & 5 & 6 & 7 \\
\hline$N_{z w}$ & $\begin{array}{c}\Phi \\
\mathrm{mm}\end{array}$ & $\begin{array}{c}n_{\text {Pmax }} \\
\mathrm{rps}\end{array}$ & $\begin{array}{c}P_{\max } \\
\mathrm{W}\end{array}$ & $\begin{array}{c}P_{20 \mathrm{rps}} \\
\mathrm{W}\end{array}$ & $\begin{array}{c}P_{35 \mathrm{rps}} \\
\mathrm{W}\end{array}$ & $\begin{array}{c}P_{50 \mathrm{rps}} \\
\mathrm{W}\end{array}$ \\
\hline 64 & 1.8 & 22 & 409 & $\mathbf{3 9 8}$ & 298 & 228 \\
\hline 42 & 2.0 & 35 & 505 & 234 & 505 & 367 \\
\hline 36 & 2.36 & 35 & 548 & 183 & $\mathbf{5 4 9}$ & 444 \\
\hline 30 & 2.36 & 45 & 555 & 116 & 474 & 521 \\
\hline 25 & 2.36 & 50 & 548 & 77 & 307 & $\mathbf{5 4 8}$ \\
\hline 20 & 2.5 & 59 & $\mathbf{5 6 3}$ & 46 & 128 & 448 \\
\hline
\end{tabular}
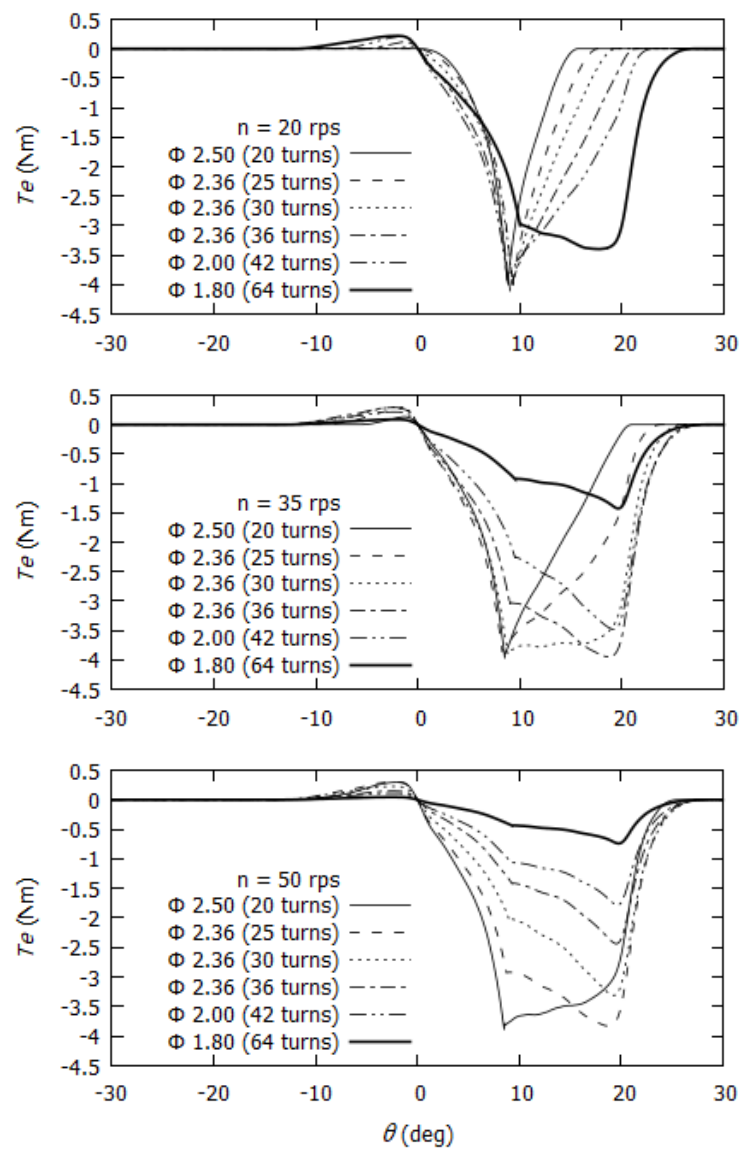

Fig. 3. Dependences of electromagnetic torque generated by one motor phase vs rotor position angle.

\section{Summary}

The maximum value of output power was obtained for the SRG with 20 turns at a speed of $59 \mathrm{rps}$. The maximum power was obtained for different winding variants at different speeds. Therefore, the choice of generator should depend on the distribution of wind speed at the installation location of the wind turbine.

\section{References}

1. A. Tomczewski, The Scientific World Journal, 2014, ID 643769

2. M. Korkosz, A. Powrozek, E3S Web of Conferences, 14, 01037 (2017)

3. W. R. H. Araujo, C. A. Ganzaroli, W. P. Calixto, A. J. Alves, G. P. Viajante, M. R. C. Reis, A. F. V. Silveira, 13th International Conference on Environment and Electrical Engineering, 1-3 Nov (2013)

4. R. T. Naayagi, V. Kamaraj, Annealing IEEE Indicon Conference, Chennai, India, 11-13 Dec. (2005)

5. M. Heidarian, B. Ganji, Power Electronics, Electrical Drives, Automation and Motion, 14271432 (2016) 